\title{
Longitudinal effects of menopausal hormone treatments on platelet characteristics and cell-derived microvesicles
}

\author{
Virginia M. Miller ${ }^{1,2}$, Brian D. Lahr ${ }^{3}$, Kent R. Bailey ${ }^{3,4}$, John A. Heit ${ }^{5}$, S. Mitchell Harman ${ }^{6}$, \& Muthuvel Jayachandran ${ }^{2}$ \\ ${ }^{1}$ Department of Surgery, College of Medicine, Mayo Clinic, Rochester, MN, USA, ${ }^{2}$ Department of Physiology \& Biomedical Engineering, Mayo Clinic, \\ Rochester, MN, USA, ${ }^{3}$ Division of Biomedical Statistics and Informatics, Mayo Clinic, Rochester, MN, USA, ${ }^{4}$ Division of Epidemiology, Mayo Clinic, \\ Rochester, MN, USA, ${ }^{5}$ Division of Cardiovascular Diseases, Internal Medicine, Mayo Clinic, Rochester, MN, USA, and ${ }^{6}$ Kronos Longevity Research \\ Institute and Phoenix VA Health Care System, Phoenix, AZ, USA
}

\section{Abstract}

Activated platelets serve as a catalyst for thrombin generation and a source of vasoactive and mitogenic factors affecting vascular remodeling. Oral menopausal hormone treatments (MHT) may carry greater thrombotic risk than transdermal products. This study compared effects of oral and transdermal MHT on platelet characteristics, platelet proteins, and platelet-derived microvesicles (MV) in recently menopausal women. Platelets and MV were prepared from blood of a subset of women $(n=117)$ enrolled in the Kronos Early Estrogen Prevention Study prior to and after 48 months of treatment with either oral conjugated equine estrogen $(0.45 \mathrm{mg} / \mathrm{day})$, transdermal $17 \beta$-estradiol $(50 \mu \mathrm{g} /$ day), each with intermittent progesterone $(200 \mathrm{mg} /$ day for 12 days a month), or placebo pills and patch. Platelet count and expression of platelet P-selectin and fibrinogen receptors were similar across groups. An aggregate measure of 4-year change in vasoactive and mitogenic factors in platelet lysate, by principle component analysis, indicated significantly lower values in both MHT groups compared to placebo. Increases in numbers of tissue factor positive and platelet-derived MV were significantly greater in the transdermal compared to placebo group. MHT was associated with significantly reduced platelet content of vasoactive and mitogenic factors representing a potential mechanism by which MHT may affect vascular remodeling. Various hormonal compositions and doses of MHT could differentially regulate nuclear transcription in bone marrow megakaryocytes and nongenomic pathways in circulating platelets thus determining numbers and characteristics of circulating MV. Thrombotic risk associated with oral MHT most likely involves liver-derived inflammatory/coagulation proteins rather than circulating platelets per se.
\end{abstract}

\section{Keywords}

Estrogen, microparticles, platelet aggregation, platelet-derived factor, thrombosis

\section{History}

Received 1 December 2014

Revised 13 February 2015

Accepted 20 February 2015

Published online 10 April 2015

\section{Introduction}

Studies of menopausal hormone treatments (MHT) on the progression of cardiovascular disease in women report conflicting conclusions, reflecting differences in study populations, timing of MHT initiation relative to the menopause, and MHT formulations and doses [1-5]. For example, while oral MHT may shift lipid metabolism to a favorable cardiovascular risk profile (i.e., decreases in low-density lipoprotein cholesterol and increases in high-density lipoprotein cholesterol), other metabolic effects due to entero-hepatic absorption of the hormones may increase liver synthesis of inflammatory cytokines and clotting factors that increase thrombotic risk [2, 6-8].

Activated platelets catalyze thrombin generation and release vasoactive and mitogenic proteins and cytokines implicated in the progression of cardiovascular disease [9-12]. Consequently, it is important to understand how different MHT formulations affect platelet functions and secretory products to establish

(C) Virginia M. Miller, Brian D. Lahr, Kent R. Bailey, John A. Heit, S. Mitchell Harman, and Muthuvel Jayachandran

Correspondence: Virginia M. Miller, PhD, Professor of Surgery and Physiology, Mayo Clinic, 200 First St. SW, Rochester, MN 55905, USA. Tel: +1 507-284-2290. Fax: +1 507-266-2233. E-mail: miller.virginia@ mayo.edu cardiovascular risk benefit profiles of various formulations [8, 13]. Activated platelets also release double membrane-bound microvesicles (MV) expressing bioactive molecules. These MV may be modulated by hormonal status. For example, the number of MV expressing tissue factor and procoagulant phospholipid (i.e., phosphatidylserine) are inversely related to plasma estrogen levels in recently menopausal women [14]. Furthermore, there is an emerging longitudinal relationship between procoagulant MV in the blood and end-organ structure, as the number of procoagulant and platelet-derived MV measured at one time point correlated with the volume of brain white matter hyperintensities in post-menopausal women 4 years later [15]. However, no studies have compared the longitudinal effects of oral and transdermal MHT on platelet function and content, and procoagulant MV number, in healthy, recently menopausal women. To address this knowledge-gap, we compared platelet characteristics, platelet proteins, and characteristics of cell membrane-derived MV in recently menopausal women randomized to either placebo, oral, or transdermal menopausal hormone treatments for 4 years. We hypothesized that platelet reactivity, pro-mitogenic proteins, and total procoagulant and platelet-derived MV would be greater in women randomized to oral compared to transdermal MHT and both would differ from women randomized to placebo. 


\section{Methods}

\section{Participants}

Study participants were recently menopausal women (42-59 years old, within 6 months to 3 years of their last menses) enrolled in the Kronos Early Estrogen Prevention Study (KEEPS) at the Mayo Clinic, Rochester, MN [16]. KEEPS was a multi-center randomized, double-blinded, placebo-controlled clinical trial designed to test the hypothesis that hormone therapy started early in menopause would reduce the progression of subclinical atherosclerosis as defined by changes in carotid artery intimamedial thickness (CIMT). Women were excluded if they had a history of or were symptomatic for cardiovascular disease; smoked more than 10 cigarettes/day; had coronary artery calcification (i.e., $\geq 50$ Agatston Units), body mass index $>35 \mathrm{~kg} / \mathrm{m}^{2}$, dyslipidemia (low-density lipoprotein cholesterol $>190 \mathrm{mg} / \mathrm{dl}$ ), hypertriglyceridemia (triglycerides, $>400 \mathrm{mg} / \mathrm{dl}$ ), $17 \beta$-estradiol $>40 \mathrm{pg} / \mathrm{ml}$; uncontrolled hypertension (systolic blood pressure $>150 \mathrm{~mm} \mathrm{Hg}$ and/or diastolic blood pressure $>95 \mathrm{~mm} \mathrm{Hg}$ ) or fasting blood glucose $>126 \mathrm{mg} / \mathrm{dl}[16,17]$; or used lipid lowering drugs. This study was approved by the Mayo Clinic Institutional Review Board (IRB \#2241-04 and \#09-003464). All participants gave written informed consent.

Each woman underwent a medical examination including body mass index, waist-hip ratio measurements, standard blood chemistries prior to and 48 months after randomization to either oral conjugated equine estrogen $(0.45 \mathrm{mg} /$ day, oCEE), transdermal 17 $\beta$-estradiol $(50 \mu \mathrm{g} / \mathrm{day}$, tE2), each with intermittent progesterone $(200 \mathrm{mg}$ /day for the first 12 days of the month), or placebo pills and patch (PL).

\section{Blood chemistries}

Total cholesterol, low- (LDL-C) and high- (HDL-C) density lipoprotein cholesterol (C), triglycerides, blood glucose, estrone (E1), 17ß-estradiol (E2), sex hormone binding globulin, testosterone, and high sensitivity C-reactive protein (hs-CRP) were measured by Kronos Science Laboratories (Phoenix, AZ) and the Mayo Clinic Department of Laboratory Medicine and Pathology (Rochester, MN). Platelet count was determined by Coulter counter [18].

\section{Blood collection and platelet activation assays}

Fasting venous blood was collected into a syringe from an antecubital venipuncture with a 19 gauge butterfly needle. Blood was dispensed into plastic tubes containing anticoagulants as indicated below and maintained at $33{ }^{\circ} \mathrm{C}$ until the test was performed. To provide consistency and to not activate the platelets, all samples were processed within 30 minutes of collection by the same individuals [19].

Platelet microaggregation was measured as the quotient of platelet counts in blood samples collected in $3.2 \%$ sodium citrate and $7.5 \%$ ethylenediaminetetraacetic acid tripotassium [EDTA (k3)] salt anticoagulants [20,21] and is reported as the percentage of the difference between the two measurements [18]. This test provides information about the sensitivity of platelets to respond to threshold stimuli. A minor share of platelets in blood collected from normal donors into citrate anticoagulant but not EDTA undergo spontaneous microaggregation, a phenomenon linked to thrombosis [22-24]. Platelet microaggregates are not counted as platelets in Coulter Counter. Therefore, differences in platelet counts between blood collected in EDTA and blood collected in citrate provides an estimate of the number of microaggregates.

Platelet dense granule ATP secretion was measured as previously described $[13,18]$.
Platelet expression of P-selectin and the fibrinogen-binding conformation of receptor integrin $\alpha_{I I b} \beta_{3}$ were measured by flow cytometry [18-20]. Non-activated (basal) and agonist-activated platelet expression of P-selectin and fibrinogen-binding receptor (PAC-1 binding) conformation were expressed as $\%$ positive platelets from total $(10000)$ platelet events.

\section{Preparation and analysis of proteins from platelet lysate and microvesicle free plasma}

Platelets were isolated from platelet-rich plasma that was separated from blood anti-coagulated with hirudin plus soybean trypsin inhibitor and sodium citrate by centrifugation at $1500 \times g$ for $10 \mathrm{~min}$. To prepare platelet lysate, the washed platelet pellet was reconstituted in $200 \mu \mathrm{l}$ lysis buffer [(\#0103004-L; Ray Biotech, Norcross, GA); with $5 \mathrm{mM}$ TRIS, $0.5 \%$ TRITON X100, and a mixture of protease inhibitors (serine, cysteine, aspartic proteases, and amino-peptidases) (\#P8340, Sigma, St. Louis, MO), pH 7.4], passed through a 26-guage needle for 8-10 times, and then sonicated for $5 \mathrm{~min}[18,25]$. Insoluble membrane debris was pelleted from the platelet lysate by centrifugation at $12000 \times g$ for 5 minutes. The concentration of total protein in the membrane debris-free lysate (supernatant) was measured by Pierce $^{\mathrm{TM}}$ BCA protein assay kit (Pierce Biotechnology, Inc., Rockford, IL). An equal amount of protein $(300 \mu \mathrm{g})$ from each woman was applied to a customized protein array membrane from Ray Biotech, Inc. (Norcross, GA). A standard protocol suggested by the manufacturer was followed.

A similar protocol was followed for diluted (1:5 in nonspecific binding blocking buffer supplied by manufacture, Ray Biotech, Norcross, GA) MV-free plasma which was obtained by centrifuging platelet-free plasma at $20000 \times g$ for 30 minutes. Platelet lysate and plasma proteins were analyzed using a customized protein array (Supplementary Material). The densities of protein signals were quantified by positive dot blot analysis of UN-SCAN-IT gel ${ }^{\mathrm{TM}}$ analysis software (Silk Scientific Inc., Orem, UT). Positive and negative controls were proprietary and included on the arrays by the manufacturer. The signal intensity of every protein measured in the platelet lysate and microvesicle-free plasma was normalized by subtracting the average background signal (negative control) and dividing by the average pixel value of the positive controls on that array. Intensity of each protein is expressed as the average of duplicate pixel values for that protein on a given array. Examples of arrays are provided in the Supplemental Figure S1 which demonstrates the absence of signal for negative controls.

\section{Characterization of blood-borne MV}

Blood-borne MV were isolated from fresh and/or frozen plateletfree plasma prepared from hirudin/soybean trypsin inhibitor anticoagulated blood [18, 26]. Total numbers of procoagulant MV expressing tissue factor or phosphatidylserine (measured by annexin $\mathrm{V}$ binding) as well as activated platelet-derived, endothelial-derived, and leukocyte-derived MV and MV expressing intercellular adhesion molecule-1 (ICAM1) and vascular cell adhesion molecule-1 (VCAM-1) were measured at baseline and after 48 months of MHT using cell specific antibodies conjugated with phycoerythrin (PE) or fluorescein (FITC) by digital flow cytometry (FACSCanto $^{\text {TM}}$; Becton Dickinson, San Jose, CA) $[14,18,19,26]$.

\section{Statistical analyses}

Descriptive statistics were used to summarize the cohort, including counts (percentages) for categorical variables and means (SD, standard deviation) or medians (IQR, interquartile 
range) for continuous variables. For comparisons of treatment, all results reported were analyzed based on the "intent to treat" approach, though "per protocol" analyses were also performed.

In general, the overall effect of treatment was assessed in regression based on a 2 degrees of freedom test, with a significant result required before proceeding with post-hoc testing of pairwise comparisons so as to not further inflate the type I error rate. With the exception of screening the overall treatment effect, analyses were uncorrected for multiple testing and thus adhered to a liberal significance level of 0.05 .

Clinical Characteristics were measured at baseline and end-ofstudy. For descriptive purposes, baseline data are reported on the pooled set of participants as treatment group comparisons via ANOVA showed no significant differences. Changes in these measures over time were compared across treatment groups based on an analysis of covariance (ANCOVA). In particular, a main effect of treatment was entered in a linear regression model to predict the end-of-study clinical measure of interest, while the corresponding baseline measure was used as an adjusting variable in the model to reduce participant heterogeneity. For hormone data which were collected only at end-of-study and tended to be skewed, a Kruskal-Wallis test was used to assess a difference in the distributions across the three treatment groups.

Platelet and plasma protein array measurements were limited to baseline and end-of-study visits on a subset of participants ( $n=30$ and 29, respectively), with the simple difference in the paired responses used to express changes over time. Due to the multitude of (and likely correlation between) variables, data reduction using principal components (PC) analysis was attempted to transform the entire set of changes into a few independent dimensions that could "explain" most of the variability in the data. Each dimension, or PC, is scored based on a linear combination of the original variables, with the first PC accounting for the highest variance possible, and each succeeding $\mathrm{PC}$ the maximum variance $\mathrm{P}$ to orthogonal constraints of the preceding PCs. With a majority of the total variance concentrated in these first few components, a higher signal-to-noise ratio is achieved while reducing the number of comparisons considerably (i.e., 30 tests reduced to 3). The scores for each PC were then tested for a treatment group difference in a second step using one-way analysis of variance (ANOVA).

Platelet and microvesicle parameters were assessed for time trends, both within and across treatment groups, based on linear regression using the generalized estimating equations (GEE) method to account for repeated measures with an exchangeable working correlation structure assumed. From this type of regression, which allowed any participant with at least one follow-up measurement in the analysis, a differential slope (change) across treatment was tested based on the interaction coefficient between a three-level group variable and time. Each continuous response variable was graphically assessed for normality, with those found to be non-normally distributed transformed as appropriate to satisfy linear regression assumptions. For ease of describing (not testing) serial data of each platelet variable, repeated measures were summarized per participant based on the change in their average follow-up value from baseline.

\section{Results}

\section{Clinical characteristics of participants}

Of the 118 women enrolled, 117 had at least one follow-up measurement; 110 women completed the study. The median (interquartile range) age and months past menopause of women for whom adequate blood samples after 48 months of treatment were available were $57(56,60)$ years and $68(60,74)$ months, respectively. Changes in phenotypic and clinical parameters considered in assessment of cardiovascular risk for participants at the Mayo Clinic site over the 48 months of the study were representative of the entire KEEPS cohort [5]. Specifically, there were no statistically significant differences in changes in body mass index, waist circumference, or systolic or diastolic blood pressure across treatment groups (Table I).

In KEEPS participants enrolled at the Mayo Clinic, changes in LDL cholesterol differed significantly across treatment groups (overall $F$-test, $p<0.001$ ), with post-hoc testing revealing that decreases in the oCEE and tE2 groups were greater than those in the PL group ( $p=0.013$ and 0.015 , respectively). There was also a significant association of treatment group with changes in triglycerides and (log-transformed) C-reactive protein (overall $F$-tests, $p \leq 0.001$ for both), with higher increases in both measures in the oCEE group compared to the tE2 $(p \leq 0.001$ for both) or PL (triglycerides, $p=0.019$; $\log$ C-reactive protein, $p \leq 0.001$ ) groups (Table I).

There were significant differences in end-of-study levels of estrone, $17 \beta$-estradiol and sex hormone binding globulin among the three treatment groups (overall ANOVA $F$-tests, $p \leq 0.001$ for each; Table II). From post-hoc testing of pairwise group contrasts, there were significantly higher serum levels of estrone and $17 \beta$-estradiol in each hormone-treated group compared to PL ( $p \leq 0.001$ for each), and in levels of sex hormone binding globulin for those treated with oCEE compared to PL $(p=0.001)$. As expected, estrone and sex hormone binding globulin were higher in the oCEE compared to the tE2 group $(p=0.024$ and 0.001 , respectively); $17 \beta$-estradiol was higher in the tE2 compared to oCEE group $(p \leq 0.001)$. The median serum $17 \beta$-estradiol level at end of study did not exceed values characteristic of menopause required for inclusion $(40 \mathrm{pg} / \mathrm{ml})$ in the study. Total serum testosterone did not differ significantly across groups (Table II).

\section{Effects of MHT on general platelet functions}

Platelet count did not differ significantly among groups at baseline or at end of study (Table III). Platelet functions were evaluated as a function of treatment and time among participants with a baseline and at least one follow-up measurement. Within the hormone-treated and placebo groups, there were nominally significant increases $(p<0.05$, uncorrected for multiple comparisons) in platelet number and agonist-activated platelet densegranular ATP secretion over time, while both basal and agonist activated expression of $\mathrm{P}$-selectin and fibrinogen receptors (PAC-1 binding) tended to decrease within groups (Table III). There were no statistically significant differences in the longitudinal changes in any of these platelet functions across treatment groups (Table III). These analyses produced similar results when repeated used in a "per protocol" approach (results not shown).

\section{Effects of MHT on platelet proteins}

For a subset of 30 participants ( $n=11$ in the tE2 group, $n=9$ in the oCEE group and $n=10$ in the PL group), quantity of platelet lysate was sufficient to perform paired analysis of changes in protein expression from baseline to 48 months after treatment (this includes four participants in the PL group in whom baseline values were imputed from corresponding measures at 6-month follow-up). Total protein measured in the platelet lysate did not differ significantly across groups either at baseline (mean \pm SD: $1611 \pm 546$ in PL, $1610 \pm 676$ in tE2 and $1738 \pm 726 \mu \mathrm{g} / \mathrm{ml}$ in oCEE; overall ANOVA $F$-test, $p=0.887$ ) or after 48 months of treatment $(2036 \pm 788$ in PL, $1689 \pm 805$ in tE2 and $2151 \pm 743 \mu \mathrm{g} / \mathrm{ml}$ in oCEE; $p=0.390$ ). The 30 proteins examined were grouped into four categories based on their source as derived 
Table I. Phenotypic and clinical variables prior to treatment (baseline) and changes in those parameters 48 months after randomization to placebo or MHT.

\begin{tabular}{|c|c|c|c|c|c|c|c|c|}
\hline$\underline{\text { Parameters }}$ & $\begin{array}{c}\text { Baseline } \\
\left(N=118^{*}\right)\end{array}$ & \multicolumn{6}{|c|}{ Changes after treatment } & $p$ Value \\
\hline Body mass index $\left(\mathrm{kg} / \mathrm{m}^{2}\right)$ & $27.1 \pm 4.2$ & $0.8 \pm 2.2$ & 39 & $0.7 \pm 2.0$ & 36 & $0.3 \pm 1.4$ & 38 & 0.453 \\
\hline Systolic blood pressure $(\mathrm{mm} \mathrm{Hg})$ & $122.2 \pm 14.0$ & $-1.7 \pm 15.2$ & 38 & $0.1 \pm 13.3$ & 36 & $-2.8 \pm 13.4$ & 38 & 0.919 \\
\hline Diastolic blood pressure $(\mathrm{mm} \mathrm{Hg})$ & $75.4 \pm 8.0$ & $0.9 \pm 9.0$ & 38 & $0.6 \pm 10.2$ & 36 & $-0.2 \pm 7.7$ & 38 & 0.870 \\
\hline Fasting blood glucose $(\mathrm{mg} / \mathrm{dl})$ & $80.1 \pm 9.3$ & $0.9 \pm 4.9$ & 42 & $-2.3 \pm 12.0$ & 35 & $0.8 \pm 8.6$ & 39 & 0.420 \\
\hline LDL cholesterol (mg/dl) & $118.5 \pm 28.1$ & $1.0 \pm 22.8$ & 42 & $-15.1 \pm 30.0$ & 35 & $-11.9 \pm 25.5$ & 39 & 0.017 \\
\hline Triglycerides (mg/dl) & $87.4 \pm 47.1$ & $12.2 \pm 39.7$ & 42 & $-7.2 \pm 25.7$ & 35 & $32.1 \pm 50.0$ & 39 & $<0.001$ \\
\hline C-reactive protein $(\mathrm{mg} / \mathrm{l})$, median (IQR) & $1.5(0.5,3.0)$ & $0.1(-0.2,0.5)$ & 42 & $0.2(-0.8,1.2)$ & 35 & $1.5(0.5,3.9)$ & 39 & $<0.001 \ddagger$ \\
\hline
\end{tabular}

Results reported as mean \pm SD unless indicated otherwise.

*Baseline measures based on $N=118$ participants except for waist circumference $(N=114)$. There were no statistically significant differences in these variables among treatment group assignment at baseline.

$\dagger p$ value tests the overall effect of treatment group ( 2 degree-of-freedom) derived from an ANCOVA model where the end-of-study measure for a given parameter is specified as the response variable and the baseline measure as an adjusting covariate, and treatment group as the main effect of interest. $\ddagger$ Due to data skewness, log-transformed values of the baseline and end-of-study measures were used in ANCOVA.

Table II. Serum hormone levels after 48 months of randomization to placebo or MHT.

\begin{tabular}{lcccr}
\hline Parameters & Placebo $(n=36)$ & tE2 $(n=34)$ & oCEE $(n=36)$ & $p$ Value $\dagger$ \\
\hline Estrone $(\mathrm{pg} / \mathrm{ml})$ & $18.0(13.5,23.5)$ & $34.0(26.0,44.0)$ & $53.0(25.0,86.0)$ & $<0.001$ \\
Estradiol $(\mathrm{pg} / \mathrm{ml})$ & $5.3(4.1,7.2)$ & $30.5(7.3,50.0)$ & $10.5(5.8,16.0)$ & $<0.001$ \\
SHBG $(\mathrm{nmol} / \mathrm{l})$ & $45.2(29.4,66.7)$ & $54.1(37.9,76.1)$ & $86.4(59.3,129.0)$ & $<0.001$ \\
Total testosterone $(\mathrm{ng} / \mathrm{dl})$ & $19.3(17.0,22.5)$ & $22.0(16.0,28.0)$ & $21.0(18.5,28.5)$ & 0.255 \\
\hline
\end{tabular}

Results reported as median (IQR).

$\dagger p$ value testing for an overall group difference using a non-parametric Kruskal-Wallis Test.

SHBG is sex hormone binding globulin.

from platelet $\alpha$-granules, characteristic of endothelial cells, characteristic of leukocytes, or derived from platelets and other cell types. In general, with 48 months of MHT (with either tE2 or oCEE), proteins in the platelet lysate appeared to decrease compared to baseline but to increase with placebo, though formal comparisons of these changes showed a nominally significant treatment difference in only one of 30 proteins (Figure 1 and Table IV). In an attempt to achieve a higher signal-to-noise ratio by reducing the dimensionality of the data, a principle component (PC) analysis was performed on the measured changes of these proteins. The eigenvalues of the correlation matrix indicated that the first three PCs account for $86 \%$ of the variability in the data, with the first PC alone explaining $70 \%$. Since the loadings of the first PC were all positive and ranged from 0.10 to 0.21 , this dimension could be interpreted more or less as a global average of the changes across all 30 proteins. The test for an overall treatment effect on the transformed changes described by the first PC was statistically significant (overall ANOVA $F$-test, $p=0.022$ ), with an average global increase in the placebo group differing from average global decreases in both the oCEE and tE2 groups ( $p=0.009$ and 0.035 , respectively; Table IV). The second and third PCs describe other dimensions (explaining 13 and $4 \%$ of the total variability, respectively) that express contrasts in the changes between the different proteins. In comparing these across treatment groups, the second PC showed no significant treatment group difference. However, the third PC differed by treatment (overall $F$-test, $p=0.026$ ) based on significantly higher values in the tE2 group compared to the PL group $(p=0.028)$ from posthoc testing. In terms of scoring, the proteins with the lowest loading values were EPO-R, E-selectin, MMP-9, MMP-2, and CRP. The major cellular origins of these proteins are cells other than platelets, while those with highest loading were L-selectin,
VEGF, TGF $\alpha$, P-selectin, and PDGF-BB. With the exception of L-selectin, which is derived from leukocytes, all others are derived primarily from platelets.

In the comparable set of proteins measured in plasma on the same subset of individuals, there were no noticeable patterns in the 4-year changes that distinguished the three treatment groups (Figure 2), and all but one protein (MMP-9) failed to show a nominally significant group difference from formal testing. After reducing the dimensionality in these changes using PC analysis, no significant treatment effects were detected for any of the first three PCs (cumulatively these accounted for $59 \%$ of the total variability).

Paired measures of proteins in platelet lysate and in plasma were compared on this subset, a total of 29 participants pooled across treatment groups. With the exceptions of CRP, E-selectin, and $\mathrm{TNF} \alpha$, protein levels differed significantly between platelet lysate and plasma, although the direction and magnitude of these differences varied. Only levels OPN, ICAM-1, CD14, L-selectin, MMP-9, and TIMP-2 were, on average, greater in plasma than platelet lysate (Table V).

\section{Effects of MHT on populations of MV}

Changes in measures from the eight MV variables collected serially over the 48 months of the study were compared across treatments. Although baseline data were limited to only 58 participants due to a lack of available samples, regression analysis testing for a differential treatment-by-time slope included all participants $(N=115)$ with at least one measurement. Among the MV variables analyzed, only changes in tissue factor-positive and platelet-derived (CD42a) MV showed nominally significant differences across the three groups $(p=0.008$ and 0.037 , 
Table III. Platelet functions prior to randomization (baseline) to placebo or MHT and changes in those functions 48 months after randomization.

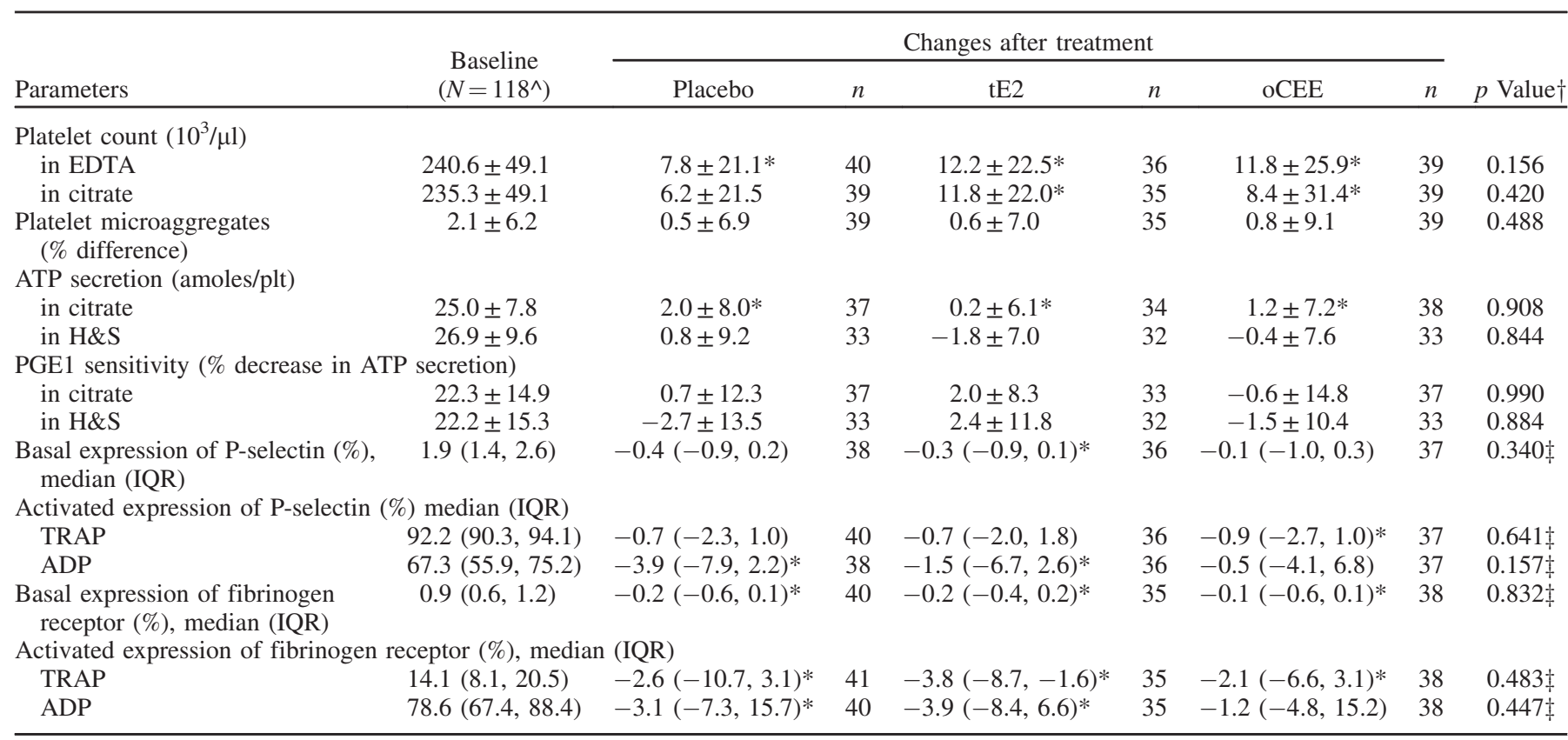

Results reported as mean \pm SD unless indicated otherwise.

$\wedge^{\wedge}$ Baseline measures of ATP H\&S amoles/platelet and H\&S PGE1 sensitivity based on $\mathrm{N}=99$ participants; all other baseline measures from 108 to 116 total participants.

$\dagger \mathrm{p}$ value derived from GEE method to correct a working independence model for within-subject correlation $(\mathrm{N}=117$ for each).

$\ddagger$ Due to data skewness, transformed values were used in the GEE modeling.

* Significant within-group change $(\mathrm{p}<0.05)$.

Abbreviations: ADP, adenosine diphosphate; ATP, adenosine triphosphate; H\&S, hirudin and soy bean trypsin inhibitor; TRAP, thrombin receptor agonist peptide.

respectively). From post-hoc testing, increases in tissue factorpositive MV in the tE2 group were significantly higher than changes observed in the PL and oCEE groups $(p=0.011$ and 0.003 , respectively), while increases in platelet-derived MV in those treated with tE2 were significantly higher only compared to those on PL ( $p=0.011$; Figure 3$)$. Longitudinal analyses of the other six MV parameters showed no evidence of a treatment difference using either the "intent to treat" or "per protocol" approach.

\section{Discussion}

This study is the first to provide a comprehensive and longitudinal evaluation of the effect of two clinically relevant MHT formulations on platelet functions, platelet-associated proteins and blood borne activated cell-membrane-derived MV in recently menopausal women. As platelets are derived from nucleated bone marrow megakaryocytes, sex steroid hormones affect gene transcription and translation and thus most platelet characteristics including receptor content, and enzyme and protein concentrations in granules. However, once in the circulation, hormonal actions on the anucleated platelets would be through non-genomic activation of membrane ion channels, receptors and post-translational regulation of proteins, receptors and enzyme activity. This study evaluated the aspects of both of these possibilities indirectly with three important and novel findings.

\section{Platelet activation}

The first important and somewhat unexpected finding was that the formulations of MHT used in KEEPS did not have significant effects on general platelet characteristics, that is, numbers of blood platelets, their spontaneous micro-aggregation or either basal or stimulated expression of surface proteins/ receptors (P-selectin or fibrinogen receptors). Spontaneous microaggregation is not a test commonly used to assess platelet function and represents an indirect measure of platelet sensitivity based on the observation that platelets undergo spontaneous aggregation in citrate but not EDTA anticoagulant. Platelet microaggregates are not counted as platelets in the Coulter Counter and therefore, differences in platelet counts between blood collected in citrate and EDTA provides an estimate of the number of microaggregates. Citrate-induced platelet microaggreagaton is increased among patients with myocardial infarction, peripheral arterial disease, and reno-vascular hypertension compared to normal controls, indicating in vivo activation of these platelets by contact with vascular lesions [20, 24, 27]. The lack of significant changes in platelet sensitivity in KEEPS participants may reflect the absence of arterial disease [5]. Alternatively, it could be argued that the doses of hormones used in KEEPS were insufficient to affect platelet functions as the median serum $17 \beta$-estradiol of participants randomized to treatment did not exceed that used to define menopausal status $(<40 \mathrm{pg} / \mathrm{ml})$ for inclusion into the study $[16,28]$. However, both hormone treatments were efficacious for relief of menopausal symptoms [5], and for maintaining bone mineral density [29], suggesting that the hormone levels achieved by the treatment and sustained throughout the study had physiological activity on other systems. Changes in platelet characteristics observed within groups, including the PL group, over the duration of the study may reflect those changes associated with chronological aging.

\section{Platelet proteins}

The second important finding was that although overall platelet sensitivity did not appear to be altered by MHT, these treatments did affect the aggregate distribution of platelet proteins in a subset of participants in whom these parameters were measured. A custom designed antibody array which included proteins 
Platelet $\alpha$ granule-associated proteins

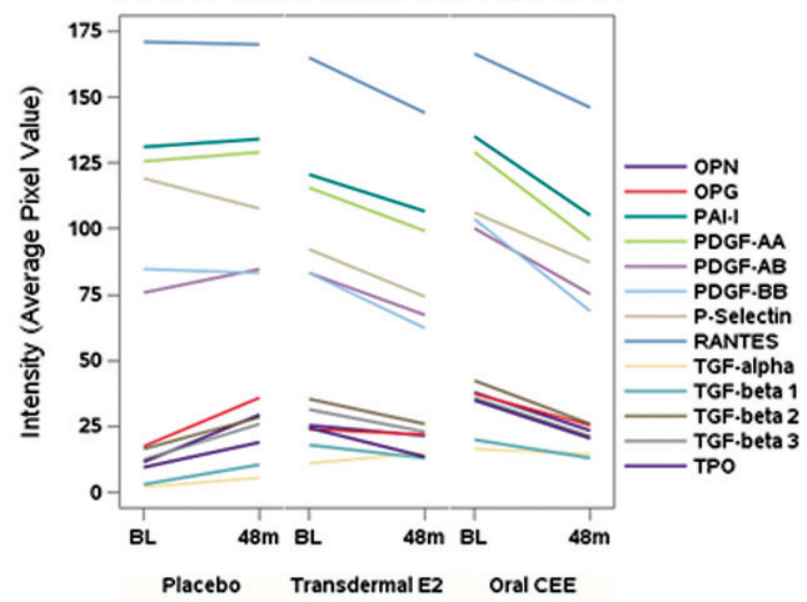

Leukocyte-associated proteins

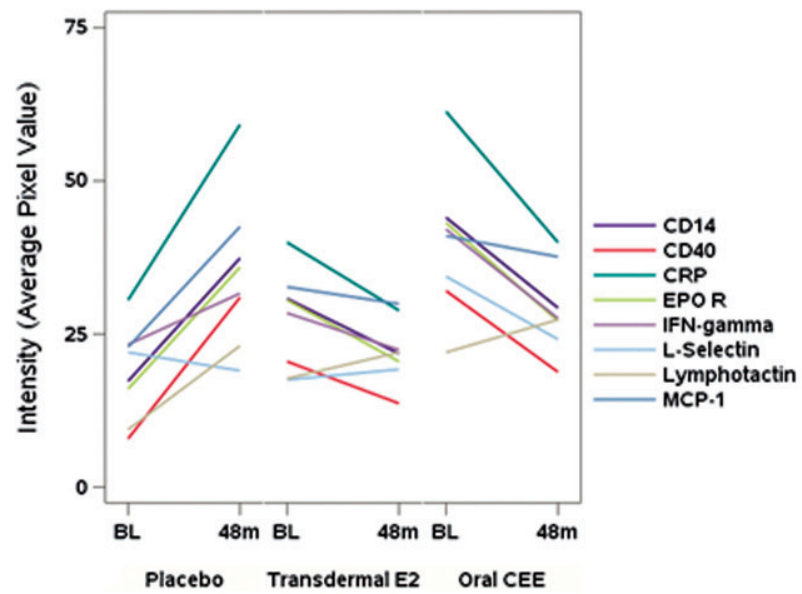

Endothelium-associated proteins

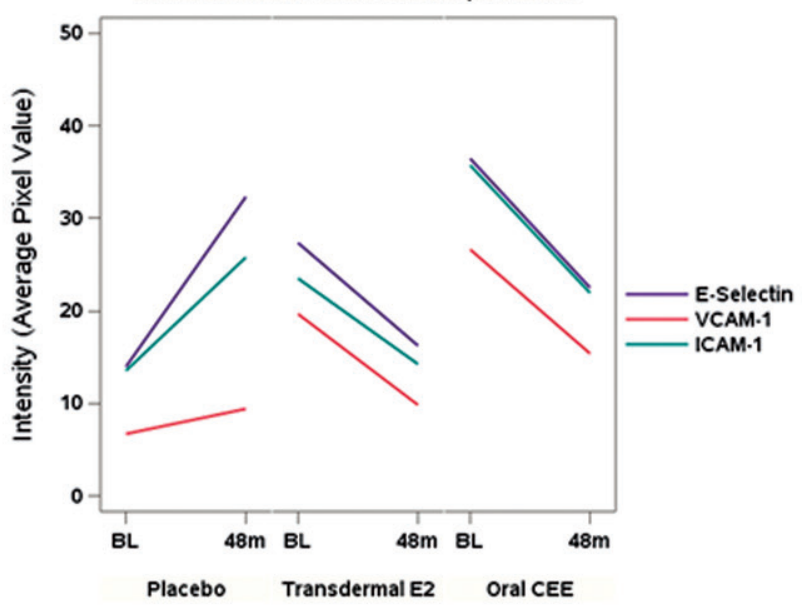

Platelet and other cell-associated proteins

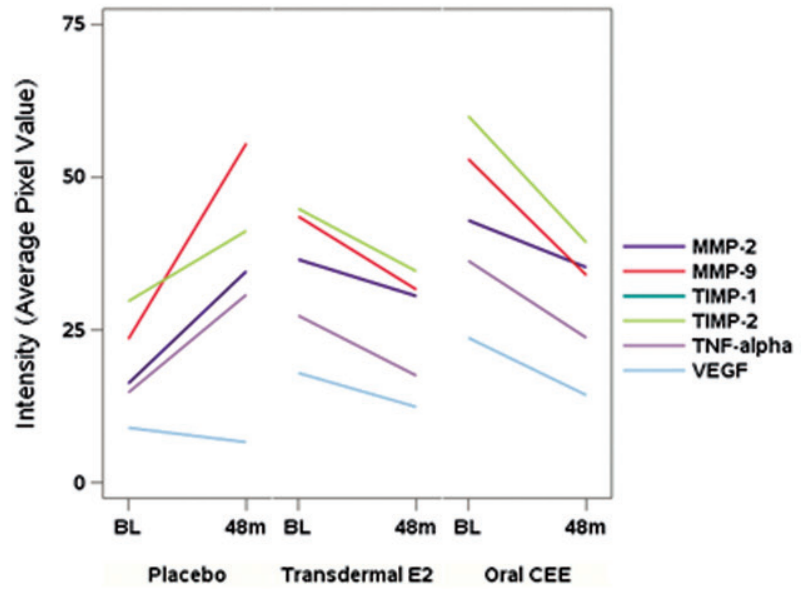

Figure 1. Mean changes in concentrations (defined by average pixel value of each protein) of proteins derived from platelet lysate collected prior to (baseline, BL) and after 48 months of randomization to either Placebo, transdermal 17 $\beta$-estradiol (E2) or oral conjugated equine estrogen (oCEE). Each bar represents the mean of pixel values per group ( $n=10$ in the placebo group, $n=11$ in the tE 2 group, and $n=9$ in the oCEE group). The proteins are grouped according to proposed cell of origin. The list of abbreviations for the proteins is provided in the Supplementary Material.

Table IV. Changes in proteins in platelet lysate after 48 months of treatment with placebo, transdermal 17ß-estradiol (tE2) or oral conjugated equine estrogen (oCEE).

\begin{tabular}{|c|c|c|c|c|}
\hline Proteins & Placebo $(n=10)$ & $\mathrm{tE} 2(n=11)$ & oCEE $(n=9)$ & $p$ Value $\dagger$ \\
\hline \multicolumn{5}{|c|}{$\alpha$ Granule-associated } \\
\hline OPN & $18.0 \pm 28.9$ & $-3.7 \pm 11.9$ & $-14.5 \pm 26.2$ & 0.172 \\
\hline OPG & $18.4 \pm 38.2$ & $-2.2 \pm 9.0$ & $-11.8 \pm 29.7$ & 0.189 \\
\hline PAI-I & $3.1 \pm 64.7$ & $-13.9 \pm 25.1$ & $-30.1 \pm 32.1$ & 0.096 \\
\hline PDG -AA & $3.3 \pm 67.9$ & $-16.3 \pm 28.5$ & $-33.2 \pm 32.0$ & 0.092 \\
\hline PDGF-AB & $8.9 \pm 40.0$ & $-16.1 \pm 18.4$ & $-24.7 \pm 31.4$ & 0.115 \\
\hline PDGF-BB & $-1.4 \pm 44.9$ & $-20.6 \pm 18.2$ & $-34.6 \pm 29.5$ & 0.119 \\
\hline P-selectin & $-11.3 \pm 45.2$ & $-18.2 \pm 11.8$ & $-19.0 \pm 16.9$ & 0.480 \\
\hline RANTES & $-0.9 \pm 73.1$ & $-20.9 \pm 49.9$ & $-20.6 \pm 38.3$ & 0.260 \\
\hline $\mathrm{TGF} \alpha$ & $3.1 \pm 9.1$ & $4.1 \pm 22.4$ & $-1.9 \pm 22.7$ & 0.572 \\
\hline TGF $\beta 1$ & $7.4 \pm 12.2$ & $-4.6 \pm 21.5$ & $-7.2 \pm 20.7$ & 0.899 \\
\hline TGF $\beta 2$ & $12.0 \pm 21.5$ & $-9.4 \pm 22.9$ & $-16.4 \pm 23.1$ & 0.437 \\
\hline TGF $\beta 3$ & $13.6 \pm 18.1$ & $-8.5 \pm 21.2$ & $-14.5 \pm 26.7$ & 0.209 \\
\hline TPO & $9.6 \pm 21.2$ & $-11.1 \pm 14.0$ & $-14.5 \pm 24.4$ & 0.243 \\
\hline \multicolumn{5}{|c|}{ Endothelium-associated } \\
\hline E-selectin & $18.3 \pm 30.8$ & $-11.0 \pm 17.2$ & $-13.9 \pm 21.0$ & 0.061 \\
\hline ICAM 1 & $12.3 \pm 25.1$ & $-9.2 \pm 15.5$ & $-13.8 \pm 19.3$ & 0.123 \\
\hline VCAM 1 & $2.7 \pm 10.4$ & $-9.8 \pm 15.4$ & $-11.2 \pm 21.2$ & 0.544 \\
\hline \multicolumn{5}{|c|}{ Leukocyte-associated } \\
\hline CD14 & $20.1 \pm 31.2$ & $-8.9 \pm 13.6$ & $-14.8 \pm 26.1$ & 0.086 \\
\hline CD40 & $23.0 \pm 34.9$ & $-6.8 \pm 13.3$ & $-13.2 \pm 23.9$ & 0.059 \\
\hline CRP & $28.6 \pm 53.9$ & $-11.0 \pm 17.9$ & $-21.2 \pm 26.0$ & 0.061 \\
\hline
\end{tabular}


Table IV. Continued

\begin{tabular}{|c|c|c|c|c|}
\hline$\underline{\text { Proteins }}$ & Placebo $(n=10)$ & $\mathrm{tE} 2(n=11)$ & oCEE $(n=9)$ & $p$ Value $\dagger$ \\
\hline EPO-R & $20.0 \pm 31.7$ & $-10.1 \pm 20.7$ & $-15.9 \pm 17.9$ & 0.079 \\
\hline $\mathrm{IFN} \gamma$ & $8.3 \pm 31.6$ & $-5.9 \pm 8.8$ & $-14.6 \pm 15.7$ & 0.303 \\
\hline L-selectin & $-3.1 \pm 13.6$ & $1.7 \pm 8.9$ & $-10.2 \pm 12.7$ & 0.499 \\
\hline Lymphotactin & $13.7 \pm 23.0$ & $4.3 \pm 17.0$ & $5.4 \pm 28.6$ & 0.822 \\
\hline MCP-1 & $19.7 \pm 28.9$ & $-2.9 \pm 14.6$ & $-3.5 \pm 23.8$ & 0.138 \\
\hline \multicolumn{5}{|c|}{ Platelet/other cell-associated } \\
\hline MMP-2 & $18.5 \pm 25.2$ & $-6.0 \pm 16.6$ & $-7.8 \pm 20.0$ & 0.251 \\
\hline MMP-9 & $32.0 \pm 39.6$ & $-11.9 \pm 17.9$ & $-18.9 \pm 20.4$ & 0.010 \\
\hline TIMP-1 & $2.2 \pm 51.1$ & $-9.6 \pm 19.8$ & $-24.6 \pm 29.1$ & 0.265 \\
\hline TIMP-2 & $11.5 \pm 34.9$ & $-10.3 \pm 16.6$ & $-20.6 \pm 23.4$ & 0.306 \\
\hline $\mathrm{TNF} \alpha$ & $16.2 \pm 34.2$ & $-9.9 \pm 15.8$ & $-12.6 \pm 20.0$ & 0.158 \\
\hline VEGF & $-2.4 \pm 8.3$ & $-5.6 \pm 10.4$ & $-9.6 \pm 13.6$ & 0.925 \\
\hline \multicolumn{5}{|c|}{ Principle components (PC) } \\
\hline PC\#1 $(70 \%)$ & $3.067 \pm 5.542$ & $-0.946 \pm 2.177$ & $-2.252 \pm 4.123$ & 0.022 \\
\hline PC\#2 (12.7\%) & $0.138 \pm 1.879$ & $-0.149 \pm 2.371$ & $0.029 \pm 1.655$ & 0.947 \\
\hline PC\#3 $(3.7 \%)$ & $-0.588 \pm 0.926$ & $0.613 \pm 0.841$ & $-0.096 \pm 1.107$ & 0.026 \\
\hline
\end{tabular}

Results reported as mean $\pm \mathrm{SD}$.

$\dagger p$ value tests the overall treatment group effect (2 degree of freedom), which was derived from an ANCOVA model for individual protein variables (adjusting for baseline values) and from an ANOVA model for each of the three principle components.
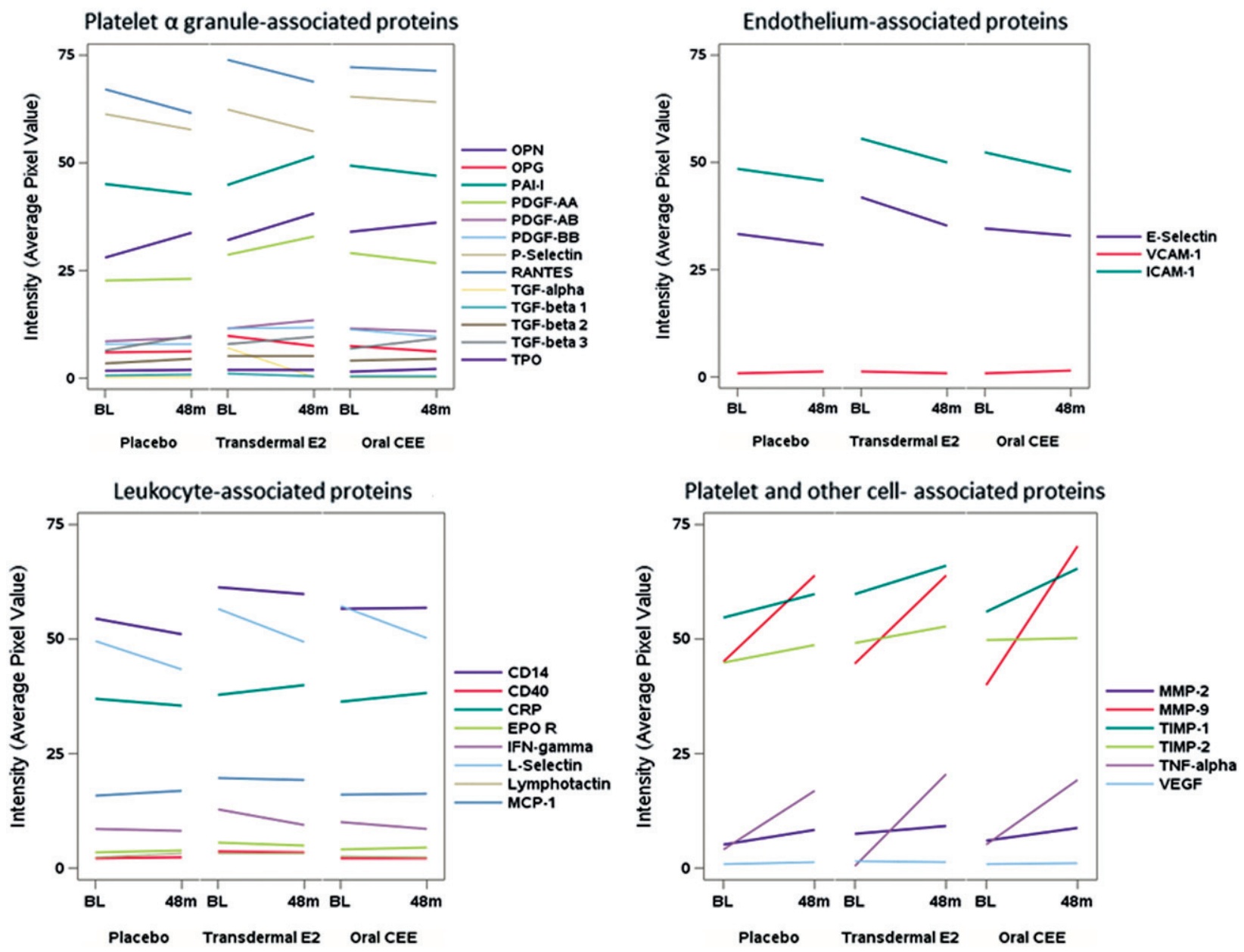

Figure 2. Mean changes in concentrations (defined by average pixel value of each protein) of proteins in plasma collected prior to (baseline, BL) and after 48 months of randomization to either placebo, transdermal 17 $\beta$-estradiol (E2), or oral conjugated equine estrogen (oCEE). Each bar represents the mean of pixel values per group ( $n=10$ in the placebo group, $n=11$ in the $\mathrm{tE} 2$ group, and $n=9$ in the oCEE group). The proteins are grouped according to proposed cell of origin. The list of abbreviations for the proteins is in Supplementary Material. 
Table V. Comparison of pixel values of proteins measured in platelet lysate and plasma 48 months after treatment with placebo, transdermal $17 \beta$-estradiol, or oral conjugated equine estrogen.

\begin{tabular}{|c|c|c|c|}
\hline $\begin{array}{l}\text { Variable (48-months } \\
\text { values) }\end{array}$ & $\begin{array}{l}\text { Platelet } \\
(n=29)\end{array}$ & $\begin{array}{l}\text { Plasma } \\
(n=29)\end{array}$ & $\begin{array}{c}p \text { (paired } \\
t \text {-test) } \\
\end{array}$ \\
\hline \multicolumn{4}{|l|}{$\alpha$ granule-associated } \\
\hline OPN & $25.0 \pm 22.1$ & $36.0 \pm 13.8$ & 0.026 \\
\hline OPG & $28.0 \pm 24.6$ & $6.7 \pm 7.7$ & $<0.001$ \\
\hline PAI-I & $115.2 \pm 33.8$ & $47.1 \pm 13.9$ & $<0.001$ \\
\hline PDGF-AA & $107.9 \pm 38.3$ & $27.6 \pm 11.1$ & $<0.001$ \\
\hline PDGF-AB & $75.2 \pm 27.1$ & $11.3 \pm 5.9$ & $<0.001$ \\
\hline PDGF-BB & $71.0 \pm 27.3$ & $9.7 \pm 8.1$ & $<0.001$ \\
\hline P-selectin & $89.6 \pm 37.5$ & $59.5 \pm 15.1$ & $<0.001$ \\
\hline RANTES & $153.9 \pm 38.6$ & $67.1 \pm 13.0$ & $<0.001$ \\
\hline $\mathrm{TGF} \alpha$ & $11.9 \pm 15.6$ & $0.3 \pm 0.4$ & $<0.001$ \\
\hline TGF $\beta 1$ & $12.1 \pm 12.8$ & $0.6 \pm 0.9$ & $<0.001$ \\
\hline TGF $\beta 2$ & $26.3 \pm 15.4$ & $4.8 \pm 3.6$ & $<0.001$ \\
\hline TGF $\beta 3$ & $23.1 \pm 18.2$ & $9.6 \pm 6.3$ & 0.001 \\
\hline TPO & $17.4 \pm 17.1$ & $2.0 \pm 1.6$ & $<0.001$ \\
\hline \multicolumn{4}{|c|}{ Endothelium-associated } \\
\hline E-selectin & $23.4 \pm 20.3$ & $32.9 \pm 13.5$ & 0.072 \\
\hline ICAM-1 & $20.4 \pm 18.1$ & $47.8 \pm 13.6$ & $<0.001$ \\
\hline VCAM-1 & $11.4 \pm 13.5$ & $1.2 \pm 1.4$ & $<0.001$ \\
\hline \multicolumn{4}{|l|}{ Leukocyte-associated } \\
\hline CD14 & $29.5 \pm 22.8$ & $55.9 \pm 13.0$ & $<0.001$ \\
\hline $\mathrm{CD} 40$ & $21.4 \pm 24.7$ & $2.7 \pm 2.7$ & $<0.001$ \\
\hline CRP & $42.6 \pm 31.6$ & $37.9 \pm 11.0$ & 0.468 \\
\hline EPO-R & $27.6 \pm 21.3$ & $4.4 \pm 4.2$ & $<0.001$ \\
\hline $\mathrm{IFN} \gamma$ & $26.6 \pm 19.9$ & $8.7 \pm 8.0$ & $<0.001$ \\
\hline L-selectin & $20.5 \pm 14.8$ & $47.5 \pm 13.1$ & $<0.001$ \\
\hline Lymphotactin & $24.5 \pm 23.7$ & $2.9 \pm 2.4$ & $<0.001$ \\
\hline MCP-1 & $36.2 \pm 26.0$ & $17.5 \pm 8.0$ & 0.002 \\
\hline \multicolumn{4}{|c|}{ Platelet/other cell-associated } \\
\hline MMP-2 & $33.2 \pm 19.4$ & $8.7 \pm 5.9$ & $<0.001$ \\
\hline MMP-9 & $40.2 \pm 29.4$ & $65.9 \pm 12.5$ & $<0.001$ \\
\hline TIMP-1 & $103.9 \pm 24.6$ & $63.7 \pm 13.6$ & $<0.001$ \\
\hline TIMP-2 & $38.2 \pm 21.8$ & $50.6 \pm 13.4$ & 0.013 \\
\hline $\mathrm{TNF} \alpha$ & $23.6 \pm 21.9$ & $18.8 \pm 10.5$ & 0.319 \\
\hline VEGF & $11.0 \pm 12.6$ & $1.2 \pm 1.1$ & $<0.001$ \\
\hline
\end{tabular}

Values are shown as median $\pm \mathrm{SD}$.

involved in vascular remodeling, some of which are also known to be modulated by estrogen at the genomic level [30-32] was used, but these selected proteins represent just a few of the bioactive materials within platelets $[33,34]$.

The two hormone treatments, relative to placebo, had comparable effects on an aggregate measure of the change in platelet proteins, with a majority of the inflammatory and mitogenic cytokines showing decreasing trends. These effects may reflect genomic actions of the hormones on megakaryocytes, as concentrations of the proteins in the platelets were greater than in the plasma. These proteins identified in the platelet lysate represent potential secretory cargo which could be released during intravascular activation. In platelets derived from ovariectomized pigs treated, the amount of platelet-derived growth factor (PDGF) released in response to platelet activation by collagen was lower in the hormone-treated groups (oral oCEE and oral E2) than in the placebo group [31]. Consistent with this observation, from data on women in this study, PDGF BB represented a positive loading variable, thus a principle component, contributing to decreases in platelet proteins derived from women randomized to MHT compared to PL. However, these variables represent total platelet content and not stimulated release of proteins. PDGF is a growth factor implicated in vascular remodeling and wound healing $[35,36]$. Other proteins with the highest and lowest load weighing are also known to contribute to cell-cell interaction, matrix remodeling, and angiogenesis. Lower concentrations of plateletassociated proteins that are characteristic of vascular endothelium and leukocytes in the hormone treated groups compared to placebo, suggest that the hormone treatments may decrease interactions among endothelium, leukocytes, and platelets. In other words, proteins identified as potentially originating from other cells indicate cell-cell interactions through microvesicles and protein exchange [37, 38].

The disequilibrium of concentrations of proteins in platelet lysate and plasma suggests an active dissociation between the two compartments. This difference underscores a potential source of variability in these proteins when plasma values are used in isolation of other sources as biomarkers for diagnosis and prognosis of disease. For example, there were several proteins whose concentrations were higher in the plasma than in the platelet lysate (OPN, ICAM-1, CD14, L-selectin, MMP-9, and TIMP-2). These differences may reflect spontaneous release of these proteins from the platelets or that these proteins were derived from other cells either blood elements or cells of the vascular wall. Indeed, some of these proteins are associated with leukocytes. MMP-9 was identified within regions of plaque instability [39] possibly contributing to increases in vascular remodeling processes and adverse events in women using hormone treatments for secondary prevention of cardiovascular disease [40].

\section{Cell-derived MV}

The third important finding of this study is that the number of tissue factor-positive MV and platelet-derived MV increased to a greater extent in the tE2 group than in the PL group. Previous studies have shown that circulating MV reflects cellular activation and the number of platelet-derived MV and phosphatidylserine (annexin V)-positive MV characterizes a procoagulant environment $[14,19]$. In addition, the number of tissue factor-positive MV in women being screened for KEEPS [14] negatively correlated with serum E2 levels. The absence of a reduction in tissue factor-positive $\mathrm{MV}$ in the $\mathrm{tE} 2$ group compared to placebo may reflect the narrow range of serum E2 levels in the blood of women on treatment with only a few individuals achieving levels $>40 \mathrm{pg} / \mathrm{ml}$ which was the limit defining menopausal status for entry into the study [16]. Estrone can be converted to $17 \beta$ estradiol and its local metabolism may account for changes in tissue factor-positive MV in the oCEE group.

Differences in numbers of platelet-derived MV among groups may reflect either: (a) increased in vivo activation of platelets in the tE2 group, (b) decreased in vivo activation of platelets in the placebo and oCEE group, or (c) adhering of MV to the vascular wall or to other blood cells, thus decreasing their numbers in the plasma in the placebo and oCEE groups. In support of the latter possibility, MV are found in atherosclerotic plaque [41-45] and numbers of platelet-derived and procoagulant MV in the blood of women prior to randomization to the MHT correlated with white matter hyper intensities in the brains of women after 48 months of treatment [15]. These observations suggest a temporal relationship of MV with end-organ structural remodeling. It is unclear how MV numbers correlate to vascular or brain structural changes during or following MHT. However, these results are hypothesis generating and such analyses will be possible with follow-up of this subset of KEEPS participants.

\section{Limitations}

It could be argued that this subset of KEEPS participants does not represent the study as a whole. However, women in this subset showed the same and predictable changes in lipids and C-reactive protein based on known effects of oral MHT preparations and 
Figure 3. Time trends (estimated by least squares means) in tissue factor positive (TF; upper panel) and platelet-derived (CD42 positive; lower panel) microvesicles in women prior to and during 48 months following randomization to either placebo, transdermal 17 $\beta$-estradiol (E2) or oral conjugated equine estrogen (CEE). Each point represents a value from an individual at the respective time point.
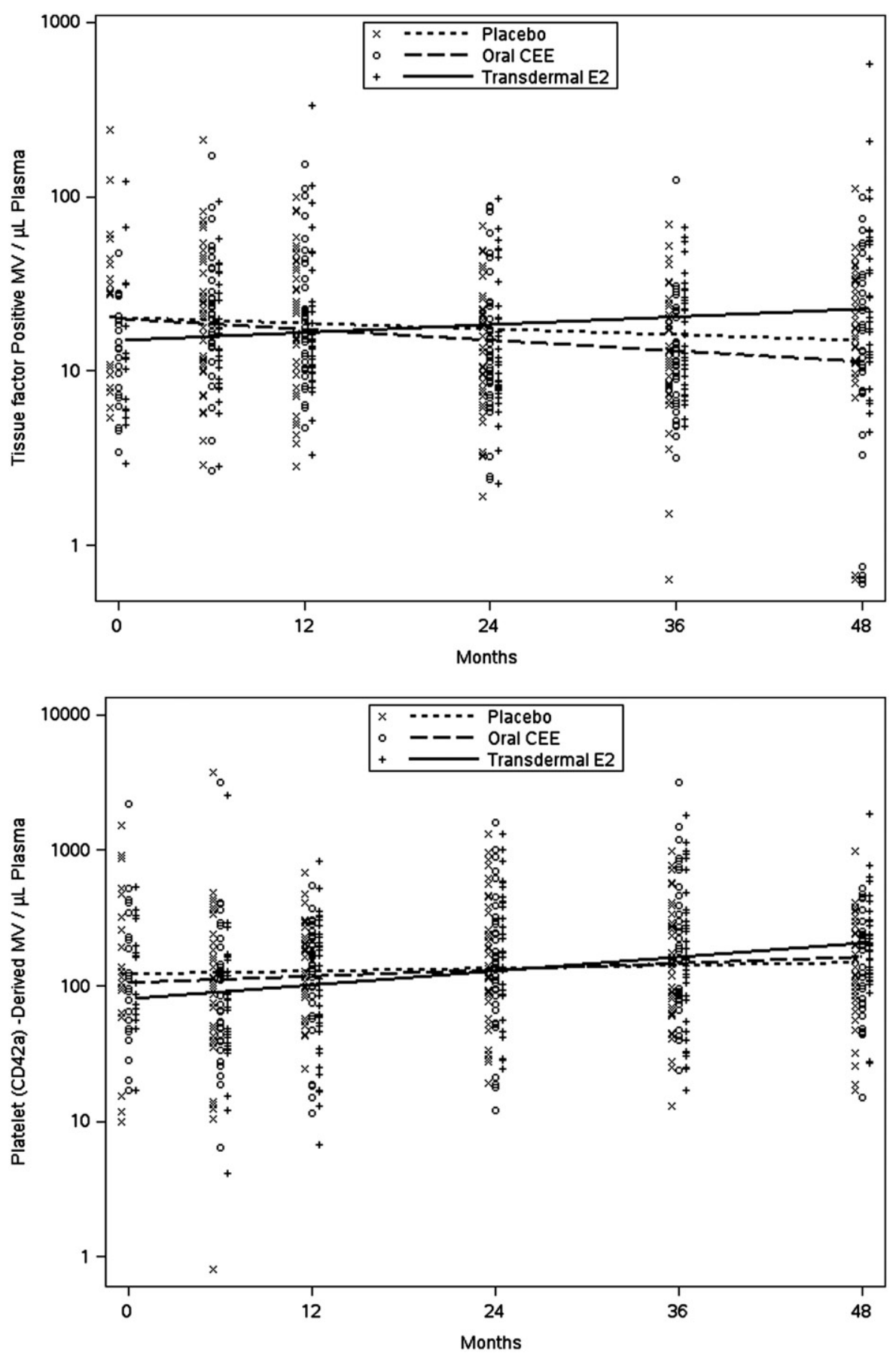

were similar to those of the entire KEEPS participants [5]. The KEEPS used lower dosages of hormones than used in other studies and therefore, results may not be comparable to what might be expected with higher doses or other formulations of hormones (i.e., continuous combined CEE with a synthetic progestogen). Platelet proteins were measured in lysate thus representing total content and not activated secretion as in other studies [31]. Finally, this analysis focused on effects of treatment alone on platelet parameters and an integrated model will need to be developed which accounts for other variable that may affect cell membrane stability (plasma lipids) and energy metabolism (glucose).

\section{Acknowledgements}

The authors thank the dedicated volunteers participating in this study and co-workers who made this possible including Robert D. Litwiller (performed platelet functional assays), Timothy M. Halling (performed platelet functional assays), Teresa G. Zais (study coordinator), and the staff in the Women's Health Clinic (clinical safety evaluations).

\section{Declaration of interest}

This work was supported by grants from the Aurora Foundation to the Kronos Longevity Research Institute, NIH HL90639, AG44170, UL1TR00013 ${ }^{1}$, American Heart Association - Scientist Development Grant, AHA 08-30503Z, American Heart Association, Grant-in-Aid, 12GRNT12050147, and the Mayo Foundation. ${ }^{1}$ From the National Center for Research Resources (NCRR), a component of the National Institutes of Health (NIH), and the NIH Roadmap for Medical Research. Contents of this paper are solely the responsibility of the authors and do not necessarily represent the official view of NCRR or NIH. Information on NCRR is available at http://www.ncrr.nih.gov/. Information on Reengineering the Clinical Research enterprise can be obtained from http://nihroadmap.nih.gov. 


\section{References}

1. Bush TL, Barrett-Connor E. Noncontraceptive estrogen use and cardiovascular disease. Epidemiol Rev 1985;7:89-104.

2. Bush TL, Barrett-Connor E, Cowan LD, Criqui MH, Wallace RB, Suchindran CM, Tyroler HA, Rifkind BM. Cardiovascular mortality and noncontraceptive use of estrogen in women: Results from the Lipid Research Clinics Program Follow-up Study. Circulation 1987; 75:1102-1109.

3. Ernster VL, Bush TL, Huggins GR, Hullka BS, Kelsey JL, Schottenfeld D. Benefits and risks of menopausal estrogen and/or progestin hormone use. Prev Med 1988;17:201-223.

4. Hodis H, Mack W, Lobo R, Shoupe D, Sevanian A, Mahrer P, Selzer R, Liu C, Liu C, Azen S. Estrogen in the prevention of atherosclerosis: A randomized, double-blind, placebo-controlled trial. Ann Intern Med 2001;135:939-953.

5. Harman SM, Black DM, Naftolin F, Brinton EA, Budoff MJ, Cedars MI, Hopkins PN, Lobo RA, Manson JE, Merriam GR, et al. Arterial imaging outcomes and cardiovascular risk factors in recently menopausal women: A randomized trial. Ann Intern Med 2014;161:249-260.

6. Scarabin PY, Alhenc-Gelas M, Plu-Bureau G, Taisne P, Agher R, Aiach M. Effects of oral and transdermal estrogen/progesterone regimens on blood coagulation and fibrinolysis in postmenopausal women: A randomized controlled trial. Arterioscler Thromb Vasc Biol 1997; 17:3071-3078.

7. Lacut K, Oger E, Le Gal G, Blouch M-T, Abgrall J-F, Kerlan V, Scarabin P-V, Mottier D, SARAH Investigators. Differential effects of oral and transdermal postmenopausal estrogen replacement therapies on C-reactive protein. Thromb Haemost 2003;90:124-131.

8. Canonico M, Oger E, Plu-Bureau G, Conard J, Meyer G, Levesque H, Trillot N, Barrellier MT, Wahl D, Emmerich J, et al. Hormone therapy and venous thromboembolism among postmenopausal women: Impact of the route of estrogen administration and progestogens: The ESTHER study. Circulation 2007;115:840-845.

9. Kurrelmeyer K, Becker L, Becker D, Yanek L, GoldschmidtClermont P, Bray PF. Platelet hyperreactivity in women from families with premature atherosclerosis. J Am Med Womens Assoc 2003;58:272-277.

10. Ross R. Cell biology of atherosclerosis. Annu Rev Physiol 1995;57: 791-804.

11. Ferroni P, Basili S, Davi G. Platelet activation, inflammatory mediators and hypercholesterolemia. Curr Vasc Pharmacol 2003;1: 157-169.

12. Calverley DC, Brass E, Hacker MR, Tsao-Wei DD, Espina BM, Pullarkat VA, Hodis HN, Groshen S. Potential role of platelet FcyRIIA in collagen-mediated platelet activation associated with atherothrombosis. Atherosclerosis 2002;164:261-267.

13. Raz L, Hunter LW, Jayachandran M, Heit JA, Miller VM. Differential effects of oral and transdermal menopausal hormone therapy on prostacyclin and thromboxane in platelets. Physiol Rep 2014;2:e00275.

14. Jayachandran M, Litwiller RD, Owen WG, Miller VM. Circulating microparticles and endogenous estrogen in newly menopausal women. Climacteric 2009;12:177-184.

15. Raz L, Jayachandran M, Tosakulwong N, Lesnick TG, Wille SM, Murphy MC, Senjem ML, Gunter JL, Vemuri P, Jack Jr CR, et al. Thrombogenic microvesicles and white matter hyperintensities in postmenopausal women. Neurology 2013;80:911-918.

16. Harman SM, Brinton EA, Cedars M, Lobo R, Manson JE, Merriam GR, Miller VM, Naftolin F, Santoro N. KEEPS: The Kronos Early Estrogen Prevention Study. Climacteric 2005;8:3-12.

17. Miller VM, Black DM, Brinton EA, Budoff MJ, Cedars MI, Hodis HN, Lobo RA, Manson JE, Merriam GR, Naftolin F, et al. Using basic science to design a clinical trial: Baseline characteristics of women enrolled in the Kronos Early Estrogen Prevention Study (KEEPS). J Cardiovasc Transl Res 2009;2:228-239.

18. Jayachandran M, Litwiller RD, Lahr BD, Bailey KR, Owen WG, Mulvagh SL, Heit JA, Hodis HN, Harman SM, Miller VM. Alterations in platelet function and cell-derived microvesicles in recently menopausal women: Relationship to metabolic syndrome and atherogenic risk. J Cardiovasc Transl Res 2011;4:811-822.

19. Jayachandran M, Litwiller RD, Owen WG, Heit JA, Behrenbeck TR, Mulvagh SL, Araoz PA, Budoff MJ, Harman SM, Miller VM. Characterization of blood borne microparticles as markers of premature coronary calcification in newly menopausal women. Am J Physiol Heart Circ Physiol 2008;295:931-938.

20. McBane II RD, Karnicki K, Tahirkheli N, Miller RS, Owen WG. Platelet characteristics associated with coronary artery disease. J Thromb Haemost 2003;1:1296-1303.

21. Jimenez TM, Patel SB, Pineda AA, Tefferi A, Owen WG. Factors that influence platelet recovery after transfusion: Resolving donor quality from $\mathrm{ABO}$ compatibility. Transfusion 2003;43:328-334.

22. Splawinska B, Furmaga W, Kuzniar J, Stawiarski M, Pikor I, Szmigiel Z, Splawinski J. Formation of prostacyclin-sensitive platelet aggregates in human whole blood in vitro. Part II. The occurrence of the phenomenon in males suffering from acute myocardial infarction. Scand J Clin Lab Invest 1987;47:125-130.

23. Wu KK, Hoak JC. Spontaneous platelet aggregation in arterial insufficiency: Mechanisms and implications. Thromb Haemost 1976;35:702-711.

24. McShine RL, Sibinga S, Brozovic B. Differences between the effects of EDTA and citrate anticoagulants on platelet count and mean platelet volume. Clin Lab Haematol 1990;12:277-285.

25. Jayachandran M, Miller VM. Ovariectomy upregulates expression of estrogen receptors, NOS, and HSPs in porcine platelets. Am J Physiol Heart Circ Physiol 2002;283:H220-H226.

26. Jayachandran M, Miller VM, Heit JA, Owen WG. Methodology for isolation, identification and characterization of microvesicles in peripheral blood. J Immunol Methods 2012;375:207-214.

27. McBane II RD, Karnicki K, Miller RS, Owen WG. The impact of peripheral arterial disease on circulating platelets. Thromb Res 2004;113:137-145

28. Karim R, Hodis HN, Stanczyk FZ, Lobo RA, Mack WJ Relationship between serum levels of sex hormones and progression of subclinical atherosclerosis in postmenopausal women. J Clin Endocrinol Metab 2008;93:131-138.

29. Farr JN, Khosla S, Miyabara Y, Miller VM, Kearns AE. Effects of estrogen with micronized progesterone on cortical and trabecular bone mass and microstructure in recently postmenopausal women. J Clin Endocrinol Metab 2013;98:E249-E257.

30. Jayachandran M, Okano H, Chatrath R, Owen WG, McConnell JP, Miller VM. Sex-specific changes in platelet aggregation and secretion with sexual maturity in pigs. J Appl Physiol 2004;97: 1445-1452.

31. Jayachandran M, Mukherjee R, Steinkamp T, LaBreche $P$ Bracamonte MP, Okano H, Owen WG, Miller VM. Differential effects of $17 \beta$-estradiol, conjugated equine estrogen and raloxifene on mRNA expression, aggregation and secretion in platelets. Am J Physiol Heart Circ Physiol 2005;288:H2355-H2362.

32. Jayachandran M, Sanzo A, Owen WG, Miller VM. Estrogenic regulation of tissue factor and tissue factor pathway inhibitor in platelets. Am J Physiol Heart Circ Physiol 2005;289:H1908-H1916.

33. Coppinger JA, Cagney G, Toomey S, Kislinger T, Belton O, McRedmond JP, Cahill DJ, Emili A, Fitzgerald DJ, Maguire PB. Characterization of the proteins released from activated platelets leads to localization of novel platelet proteins in human atherosclerotic lesions. Blood 2004;103:2096-2104.

34. Wijten P, van Holten T, Woo LL, Bleijerveld OB, Roest M, Heck AJ, Scholten A. High precision platelet releasate definition by quantitative reversed protein profiling - Brief report. Arterioscler Thromb Vasc Biol 2013;33:1635-1638.

35. Ross R. Platelet-derived growth factor. Lancet 1989;1:1179-1182.

36. Ross R. Atherosclerosis: The role of endothelial injury, smooth muscle proliferation and platelet factors. Triangle 1976;15:4551.

37. Xiong J, Miller VM, Hunter LW, Li Y, Jayachandran M. Leukocyteand platelet-derived microvesicle interactions following in vitro and in vivo activation of toll-like receptor 4 by lipopolysaccharide. PLoS One 2011;6:e25504

38. McIntyre TM, Prescott SM, Weyrich AS, Zimmerman GA. Cell-cell interactions: Leukocyte-endothelial interactions. Curr Opin Hematol 2003; 10:150-158.

39. Lewandowski KC, Komorowski J, Mikhalidis DP, Bienkiewicz M, Tan BK, O’Callaghan CJ, Lewinski A, Prelevic G, Randeva HS. Effects of hormone replacement therapy type and route of administration on plasma matrix metalloproteinases and their tissue inhibitors in postmenopausal women. J Clin Endocrinol Metab 2006; 91:3123-3130.

40. Herrington DM, Fong J, Sempos CT, Black DM, Schrott HG, Rautaharju P, Bachorik PS, Blumenthal R, Khan S, Wenger NK. 
Comparison of the heart and estrogen/progestin replacement study (HERS) cohort with women with coronary disease from the National Health and Nutrition Examination Survey III (NHANES III). Am Heart J 1998;136:115-124.

41. Chironi G, Simon A, Hugel B, Del Pino M, Gariepy J, Freyssinet JM, Tedgui A. Circulating leukocyte-derived microparticles predict subclinical atherosclerosis burden in asymptomatic subjects. Arterioscler Thromb Vasc Biol 2006;26: 2775-2780.

42. Boulanger CM, Amabile N, Tedgui A. Circulating microparticles: A potential prognostic marker for atherosclerotic vascular disease. Hypertension 2006;48:180-186.
43. Pirro M, Schillaci G, Paltriccia R, Bagaglia F, Menecali C, Mannarino MR, Capanni M, Velardi A, Mannarino E. Increased ratio of $\mathrm{CD} 31+/ \mathrm{CD} 42-$ microparticles to endothelial progenitors as a novel marker of atherosclerosis in hypercholesterolemia. Arterioscler Thromb Vasc Biol 2006;26:2530-2535.

44. Wang JM, Huang YJ, Wang Y, Xu MG, Wang LC, Wang SM, Tao J. Increased circulating CD31+/CD42- microparticles are associated with impaired systemic artery elasticity in healthy subjects. Am J Hypertens 2007;20:957-964.

45. Loyer X, Vion AC, Tedgui A, Boulanger CM. Microvesicles as cellcell messengers in cardiovascular diseases. Circ Res 2014;114: 345-353.

Supplementary Material available online.

Supplemental Figure S1. 